\title{
Hindcasting of surge and wave on Hokkaido coasts by winter low pressure system using surge-wave coupled sea bottom and surface stresses in SuWAT
}

\author{
Kenzo Kumagai, Pacific Consultants Co. LTD., kenzou.kumagai@os.pacific.co.jp \\ Sooyoul Kim, Tottori University, sooyoul.kim@sse.tottori-u.ac.jp \\ Daiki Tsujio, Pacific Consultants Co. LTD., daiki.tsujio@os.pacific.co.jp \\ Mase Hajime, Kyoto University, mase.hajime.5c@kyoto-u.ac.jp \\ Takahito Tsuji, Pacific Consultants Co. LTD., takahito.tsuji@ss.pacific.co.jp
}

\section{INTRODUCTION}

Typhoon-induced storm surge can cause catastrophic consequences in low-lying city areas on coasts. From the historical observations, it is found that Winter Low Pressure System (WLPS) has impacts similar to a typhoon in terms of surge and wave generation. For instance, from 16th to 17th in December 2014, a winter low pressure system of $951 \mathrm{hPa}$ occurred in Hokkaido, Japan, generated a surge of $1.75 \mathrm{~m}$ high and flooded many low-lying regions on the Kushiro coast (see Fig.1). This was the record-break surge level due to WLPS in Japan, since the WLPS-induced surge of $0.9 \mathrm{~m}$ was recorded in 1994.

\section{METHODOLOGY}

In this study, we have carried out a series of numerical simulations using a coupled model of surge, wave and tide (SuWAT, Kim et al. 2008) with the two-level downscaling domains with grid sizes from $927 \mathrm{~m}$ to $309 \mathrm{~m}$, respectively. The SuWAT model takes into account a wind speedlimited wave dependent drag (Kim et al., 2015) in the sea surface layer and a wave-surge interacted roughness drag (Signell et al., 1990) in the bottom layer, to improve the prediction of the WLPS-induced surge level. In the numerical experiments, we set wind speeds at 20,25 and $30 \mathrm{~m} / \mathrm{s}$ for the capped-wave dependent drag. Two different roughness approaches were used for the bottom drag: Manning's numbers and wave-surge interacted drags using the Grant and Madsen model (Madsen et al. 1988). The wave and the surge are concurrently driven by winds and atmospheric pressure field, estimated by a weather forecast model of Japan Meteorological Agency. Field surveys for the surge and wave along the Kushiro coast were also carried out for model validation.

\section{RESULTS AND CONCLUSIONS}

Figure 2 shows the comparison of the computed and measured surge levels with the drag forces of wind capped-wave dependent and surge-wave interacted bottom at Nemuro. Figure 3 shows the comparison of the calculated and observed wave heights and periods when using the $20 \mathrm{~m} / \mathrm{s}$ wind speed-capped wave dependent drag. The results indicate that the coupled model of wave and surge could estimate the observed surge and wave levels using the wave-surge interacted bottom drag as well as the capped-wave dependent drag at $25-30 \mathrm{~m} / \mathrm{s}$. From the field survey, it was found that the inundated heights on land were $70 \mathrm{~cm}$ high below ground levels of $2 \mathrm{~m}$, due to the high surge level shown in Fig.2. It is found that the track of WLPS on December 2014 was the catastrophic track, which easily generates the highest surge level at the study site. The present study highlights that the coupled effect in the bottom and sea surface layers on the wave level and wave is significant, especially, in shallow water. In addition, the wave is more sensitive to the depletion at wind speed in this event.

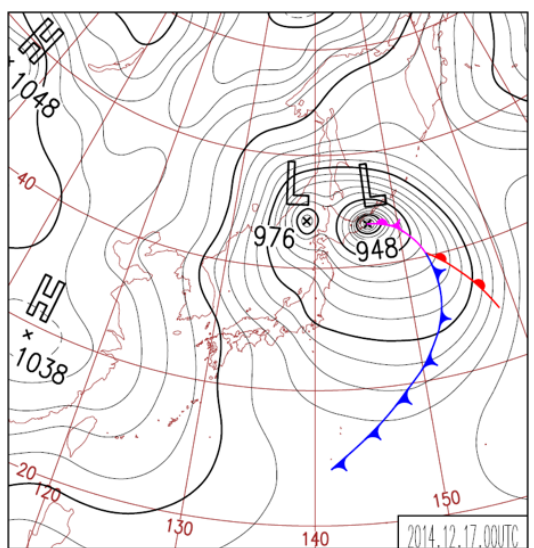

Figure 1 - Weather chart of the winter low pressure system at 9:00 17th December 2014 (JST)

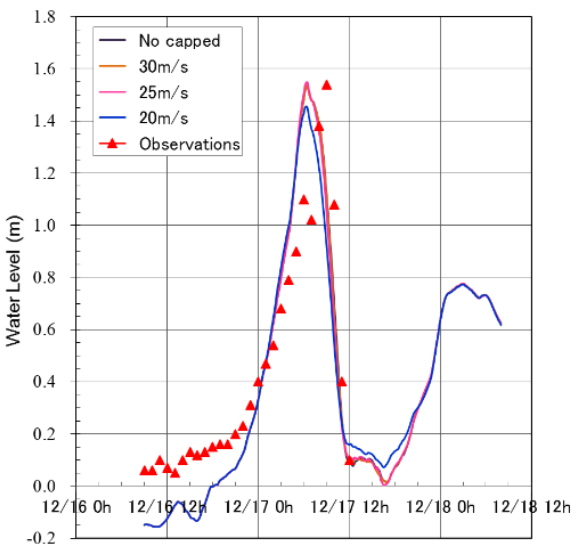

Figure 2 - Comparisons of calculated and measured surge levels with the drag forces of wind-capped wave dependent and surge-wave interacted bottom at Nemuro

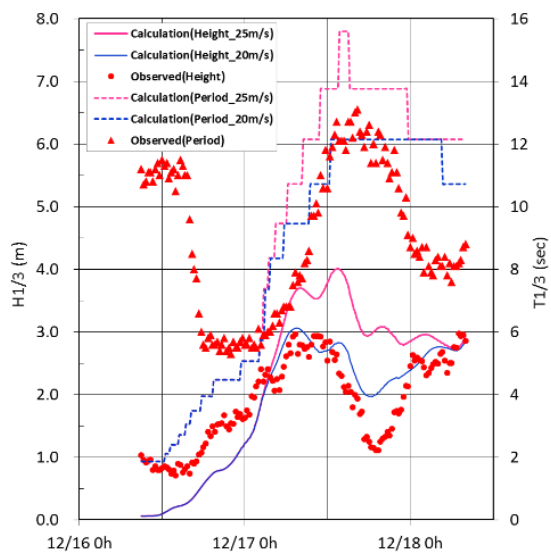

Figure 3 - Comparisons of calculated and measured wave information using the 20 and $25 \mathrm{~m} / \mathrm{s}$ wind speed-capped wave dependent drag forces 